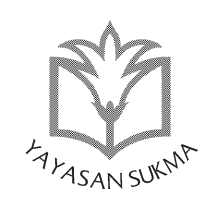

SUKMA: JURNAL PENDIDIKAN

ISSN: 2548-5105 (p), 2597-9590 (e) Volume 3 Issue 1, Jan-Jun 2019, pp. 19-33 https://doi.org/10.32533/03102.2019 www.jurnalsukma.org

\title{
AKTUALISASI WACANA CRITICAL PEDAGOGY MENUJU PENDIDIKAN INKLUSIF
}

\section{Yadri Irwansyah}

Sekolah Tinggi Keguruan dan Ilmu Pendidikan Lubuklinggau, Indonesia

email: yadriirwansyah@gmail.com

\section{Abstrak}

Penelitian ini bertujuan untuk melihat sejauh mana pengaktualisasian wacana critical pedagogy dapat membentuk satu model pendidikan baru yang lebih inklusif sekaligus anti diskriminasi terhadap kelompok-kelompok yang sulit mendapat akses pendidikan, baik karena keterbatasan biaya maupun fisik. Penelitian ini merupakan penelitian literatur dengan mengumpulkan dan mengkaji sumber-sumber referensi buku dan tulisan-tulisan lain yang relevan terhadap penelitian ini. Dengan menganalisis dan menghubungkan antara teori dan temuan fakta di lapangan, penelitian ini meyimpulkan bahwa critical pedagogy adalah satu 
konsep kritis dalam pendidikan yang menginginkan semua unsur yang terlibat dalam institusi pendidikan, dari mulai penyelenggara administrasi pendidikan, pendidik dan peserta didik memiliki kemampuan untuk membaca dan melihat fenomena-fenomen yang terjadi di dunia pendidikan kita pada hari ini, tidak hanya berdiam diri dan berpangku tangan terhadap masalah-masalah pendidikan, sehingga praktik-praktik eksklusi terhadap peserta didik bisa dihindari. Hasil dari rekomendasi pemahaman tersebut adalah kebijakan-kebijakan yang terukur terhadap mereka yang kekurangan biaya dan kelompok yang memiliki kebutuhan khsusus.

Kata Kunci: Critical pedagogy, pendidikan inklusif, perubahan sosial, critical thinking, the new sociology of education

\section{A. Pendahuluan}

Pendidikan adalah salah satu media penting untuk melakukan perubahan sosial di masyarakat, dalam pendidikan terdapat proses tansformasi ilmu pengetahuan dari pendidik ke peserta didik, yang kemudian akan di aktualisasikan oleh peserta didik di masyarakat tempat lingkungan sosialnya. Dalam hal ini pendidikan memiliki peranan yang sangat besar karena kemajuan suatu bangsa dapat dilihat dari mutu dan kualitas pendidikanya sendiri.

Sesuai dengan slogan pendidikan kita pada hari ini adalah untuk mencerdaskan kehidupan bangsa, artinya secara universal pendidikan diperuntukan kepada seluruh lapisan rakyat Indonesia tanpa membedakan status sosial, suku, agama dan kondisi fisiknya. Namun aktualisasinya di lapangan sangat berbeda tidak semua kalangan itu berkempatan mendapatkan pendidikan hanya orang-orang tertentu saja yang bisa mengakses pendidikan kita pada hari ini.

Seperti hanya orang- orang yang mempunyai kapital dan 
modal bisa menikmati pendidikan, sedangkan orang-orang dari golongan yang kurang beruntung tidak berkecupukan secara ekonomi sangat sulit mengakses pendidikan, dikarnakan biaya pendidikan yang begitu mahal, ditambah lagi orang-orang yang kebutuhan khusus yang tidak sempurna secara fisik seolah-olah di diskriminasi dan akses untuk mendapatkan pendidikan dipersulit (Prasetyo 2010, 12).

Masalah-masalah inilah yang kemudian menjadi perhatian yang cukup serius olah bebarapa kalangan akademisi yang kritis melihat fenomena-fenomena yg terjadi pada dunia pendidikan pada hari ini, untuk membaca dan menganalisa fenomena-fenomena semacam ini diperlukan pemikiran yang kritis dalam pendidikan yang di sebut critical pedagogy, agar praktek-praktek diskriminasi dalam dunia pendidikan bisa dihilangkan.

\section{B. Konsep Dasar Critical Pedagogy}

Critical pedagogy (Pendidikan kritis) adalah mazhab pendidikan yang menyakini adanya muatan politik dalam semua aktifitas pendidikan, aliran ini dalam diskursus pendidikan disebut juga "aliran kiri" karena orientasi politiknya yang berlawanan dengan mahzab liberal dan konservatif, dalam konteks akademik, mahzab ini disebut dengan "the new sociology of education" atau "critical theory of education."Henry Giroux (1993) menyebut mahzab ini dengan pendidikan radikal (radikal education), mahzab ini tidak mempresentasikan satu gagasan yang tunggal dan homogen. Namun para pendukung mahzab ini disatukan dalam satu tujuan yang sama yaitu memberdayakan kaum tertindas dan mentransformasi ketidakadilan sosial yang terjadi di masyarakat melalui media pendidikan (Nuryatno 2008, 1).

Visi dari critical pedagogy dilandaskan pada satu pemahaman bahwa pendidikan tidak bisa dipisahkan dari konteks sosial, kultural, ekonomi dan politik yang lebih luas, institusi pendidikan tidaklah netral, independen dan bebas dari berbagai kepentingan, tapi justru menjadi bagian dari institusi sosial lain yang menjadi ajang pertarung kepentingan. Pendidikan harus 
dipahami dalam rangka relasi-relasi pengetahuan, kekuasaan dan ideologi. Berbagai kepentingan inilah yang akan membentuk wajah institusi pendidikan dan mempengaruhi subjektifitas peserta didik. Harus disadari, subjektifitas manusia tidak dapat dipisahkan dari konteks sosial yang lebih luas. Subjektifitas manusia sangat dipengaruhi oleh apa yang dibaca dan dipelajari, lingkungan sekolah tempat manusia belajar, lingkungan sosial tempatnya berinteraksi, lingkungan keluarga tempat dia tinggal, sistem politik yang mengatur kehidupan publik, media massa dan televisi yang meyuplai informasi publik dan entitas-entitas lain yang turut membentuk dan mempengaruhi kesadaran individu.

Dalam konteks diatas, perlu membangun kesadaran kritis peserta didik agar mampu mendemistifikasi kepentingan ideologis yang menyelimuti realitas, kesadaran kritis merupakan kata kunci yang sangat penting, sebab penindasan, dominasi dan eksploitasi itu berlangsung karna terdegredasinya pikiran kritis manusia. Apa yang dimaksud dengan critical thinking / consciousness di sini adalah mode of thought yang mampu menyingkap fenomena-fenomena tersembunyi atau melampaui asumsi-asumsi yang hanya berdasarkan, meminjam istilah Antonio Gramsci (1971), "Common sense" akan tetapi harus di ingat bahwa mengembangkan pikiran kritis tidak bisa didepositokan atau di impose dari luar tapi harus dilahirkan lewat usaha kreatif dalam diri individu itu sendiri.

Mahzab pendidikan kritis berbasis pada keadilan dan kesetaraan. Oleh karena itu, pendidikan tidak hanya berkutat pada pertanyaan seputar sekolah, kurikulum dan kebijakan pendidikan, tapi juga tentang keadilan sosial dan kesetaraan. Visi sosial dan pendidikan yang berbasis pada keadilan sosial dan kesetaraan ini tidak hanya tertuang dalam tulisan dan kata, tapi juga termanisfestasikan dalam praktek pendidikan sehari-hari. Tidak boleh ada ambiguitas, paradoksal, dan ketidak-konsistenan antara apa yang dikontruski secara normatif dengan praktek di lapangan. Fakta menunjukan sekolah sering kali menunjukan wajah yang ambigu, kontradiktif dan paradox ((Nuryatno 2008, 3). 
Di satu sisi, sekolah dilandaskan pada satu visi untuk membangun masyarakat yang demokratis, namun justru pada prakteknya bertindak otoriter dan anti-demokrasi dengan tidak member ruang bagi tumbuhnya subjek yang kritis, toleransi dan multikulturalisme. Sekolah punya selogan "mencerdaskan anak bangsa" tapi pada prakteknya hanya untuk anak bangsa yang punya modal dan kapital. Sekolah punya visi untuk menjunjung tinggi persamaan derajat, tapi pada prakteknya tidak mengakomodasi kaum minoritas terutama kaum difabel. Sekolah terlanjur di persepsi sebagai media belajar bagi semua, tapi dalam prakteknya hanya mengakomodasi anak yang pintar, pandai, dan cerdas dan mengeksklusi mereka yang punya keterbatasan intelektual. Wajah paradoksal pendidikan seperti ini harus segera diakhiri agar tidak tidak memunculkan sindiran-sindiran yang tajam di public seperti "sekolah itu candu" (Roem Topatimasang, 2004), "Orang miskin dilarang sekolah" (Eko Prasetyo), atau orang bodoh dilarang sekolah.

Kritik menjadi bahasa yang melekat dalam mahzab pendidikan kritis, dan mahzab ini menjadikan "language of critique" sebagai landasan berpijak untuk mengkontruksi bangunan epistemologi dan praksisnya. Bahasa kritik ini dikemukakan dalam karya-karya Mahzab Frankfrut, Paulo freire dan Antonio gramsci, dan oleh karena itu ketiganya menjadi rujukan utama dari mahzab pendidikan kritis. Seiring dengan perkembangan waktu ketiga sumber ini kemudian ditambah dengan wacana pos moderenisme dan feminisme karena pengaruhnya yang luar biasa dalam ilmu sosial.

Memasukan Mazhab Frankfrut dan pos modernisme dalam satu paying rujukan bukanya tanpa masalah, sebab keduanya berangkat dari titik tolak yang berbeda. Mazhab Frankfrut, yang masih meyakini proyek modernisme, bertitik tolak pada asumsi perlunya meletakkan fondasi dasar bagi kehidupan masyarakat modern dengan bertumpu pada universalisme akal, hak dan otonomi individu sedangkan pos modernisme, kebalikanya tidak meyakini apa yang disebut universalisme, yang ada adalah partikularitas, prulalitas, dan keberagaman. Mazhab Frankfurt masih 
mendukung dan sekaligus kritis terhadap proyek enlihtement, sedangkan grand-narrative karena ia menolak peletakan pondasi permanen apapun atas realitas dan kebenaran. Dalam pandangan posmodernisme, tidak ada kebenaran sejati yang karena yang disebut dengan kebenaran itu sebenarnya hanyalah interpretasi manusia atas realitas dengan medium bahasa. Bukan kebenaran atas realitas itu sendiri yang dihasilkan, tapi cuma konstruksi bahasa manusia, dengan demikian pos modernisme menganut paham relativisme. Mahzab pendidikan kritis mengambil unsur konstruktif dari Mahzab Frankfurt dan posmodernisme yang bisa dicangkokkan dalam upaya mengkontruksi satu bentuk pendidikan yang membebaskan dan memanusikan manusia, artinya pendidikan harus bisa menjadi medium bagi kritik sosial dan sekaligus mampu menawarkan kemungkinan-kemungkinan dikembangkanya.

Salah satu tema pokok mahzab pendidikan kritis adalah tentang kapitalisme karena pengaruhnya yang besar dalam kehidupan masyarakat modern, apa yang dilahirkan dari rahim kapitalisme adalah culture positivisme dan rasionalitas, satu bentuk budaya dan model berfikir yang berpengaruh atas laju arah pendidikan, karena ilmu yang disampaikan kepada peserta didik dalam budaya ini adalah ilmu yang mengorientasikan mereka untuk beradaptasi dengan dunia masyarakat industri.

Proses pembelajaran pun ditekankan pada upaya untuk mengakumulasi dan memiliki ilmu pengetahuan yang ditujukan untuk mengejar profit. Jadilah pembelajaran sebagai arena imposisi pengetahuan dari mereka yang menganggap tahu segalanya kepada mereka yang tidak mengetahui apa-apa. Lebih dari itu dalam budaya positivisme, pengetahuan cendrung dipisahkan dari proses pembentukanya seolah-olah keduanya bisa dipisahkan, pengetahuan dianggap sebagai barang jadi, yang siap ditelan oleh peserta didik tanap melalui proses seleksi dan refleksi bersama.

Dari perspektif pendidikan kritis, sekolah diyakini memainkan peran yang signifikan dalam membentuk kehidupan politik 
Aktualisasi Wacana Critical Pedagogy Menuju Pendidikan Inklusif

dan kultural. Sekolah adalah media untuk meyiapkan dan melegitimasi bentuk-bentuk tertentu kehidupan sosial. Pendidikan dimaknai lebih dari sekedar persoalan penguasaan teknik-teknik dasar yang diperlukan dalam masyarakat industri, tepati juga diorientasikan untuk lebih menaruh perhatian pada isu-isu fundamental dan esensial, seperti meningkatkan harkat kemanusian meyiapkan manusia untuk hidup di dan bersama dunia dan mengubah sistem sosial yang berpihak pada kaum marginal (Nuryatno 2008, 6).

\section{Basis Teori Pendidikan Kritis}

Sumber yang kemudian menjadi rujukan sebagai basis teori dan metodologi mazhab pendidikan kritis ada tiga: toeri mazhab Frankfurt, Antonio Gramsci, Paulo Freire. Ketiga sumber ini sudah sangat populer bagi mereka yang punya perhatian terhadap teori-teori ilmu sosial, khususnya teori ilmu sosial kritis. Saat ini adalah masa di mana tidak ada eksklusifitas bidang keilmuan. Artinya, apa yang berkembang dalam satu disiplin ilmu dapat mempengaruhi disiplin ilmu yang lain. Teori ilmu sosial mazhab frankfurt, misalnya sangat berpengaruh terhadap berbagai bidang keilmuan lain seperti filsafat, sosiologi, politik, hukum dan pendidikan. Aktivitas politik Gramsci yang kemudian mengahsilkan karya "the prison notebook" juga berpengaruh di berbagai disiplin ilmu seperti culture studies, politik, pendidikan, filsafat, literatur dll, sedangkan teori pendidikan Freire juga berpengaruh terhadpan disiplin ilmu yang lain seperti politik, culture studies, psikologi dan sosiologi. Ini menandakan bahwa perkembangan satu disiplin ilmu sangat memungkinkan untuk mempengaruhi disiplin ilmu yang lain. Tidak ada monopoli satu teori hanya berpengaruh terhadap satu disiplin ilmu tertentu dimana teori tersebut berasal. Kita akan coba membahas satu persatu ketiga sumber ini, terutama menyangkut pengertian apa dan siapa dan pokok -pokok ketiga pikiran sumber ini: 


\section{Teori Kritis Mazhab Frankfurt}

Istilah "critical theory" pertama kali diperkenalkan oleh Max Horkheimer (1985), pada mulanya istilah ini hanya merujuk secara khusus kepada tradisi teori mazhab frankfrut. Tetapi, seiring dengan perkembangan ilmu sosial istilah tersebut mempunyai konotasi yang lebih luas, termasuk di dalamnya tradisi teori posmodernisme dan feminisme. Mazhab Frankfurt berdiri di atas tradisi Jerman, mazhab ini tidak mempresentasikan gagasan yang tunggal, tapi plural namun begitu pandangan-pandangan mazhab ini berakar pada tradisi Kant, Hegel, Frued dan khususnya Marx. Perhatian utamanya adalah membangun sebuah teori yang rasional dan dapat menghasilkan emansipasi manusia dalam masyarakat industry (Jay 2005, 45).

Cukup problematis untuk mendefinisikan secara pasti apa itu teori kritis, sebab konstruksinya tidak dibangun dari gagasan yang tunggal dan pasti, namun ada satu karateristik utama dari teori ini, yakni bahwa teori sosial harus memainkan peranan yang signifikan dalam mengubah dunia dan meningkatkan kondisi kemanusian. Herbert Marcuse, sebagaimana yang diulas oleh Harold Bleich, memberikan tiga prinsip teori kritis.

Pertama, ia secara integral ia berkaitan dengan realitas kongkrit, wilayah diskursusnya adalah realitas sosial, bukan berada dalam alam abstrak dan historis. Penekanan terhadap tema-tema yang diusung seperti dominasi, hegemoni, totalitarianisme dan emansipasi. Teori ini punya perhatian terhadap praksis yang di didesain untuk mengubah struktur yang dominan di masyarakat dan berusaha untuk membuka jalan bagi kebebasan manusia dan mengeliminasi represi (Bourdieu 2016, 69).

Prinsip kedua berkaitan dengan fungsi teori kritis. Fungsi teori kritis adalah untuk menguji secara kritis kontradiksi-kontradiksi yang terjadi dalam masyarakat dan berupaya menjadi akar penyebabnya dengan membongkar apa yang tersembunyi dan membuat yang implisit menjadi eksplisit. Ini berarti analisis yang dibangun sudah memasuki deep structure, bukan lagi pada wilayah surface structure. Prinsip ketiga adalah berkaitan dengan 
Aktualisasi Wacana Critical Pedagogy Menuju Pendidikan Inklusif

penggunaan beberapa idealitas masa lalu untuk menilai situasi sekarang. ini berarti teori kritis tidak menafikan nilai-nilai tersebut bermanfaat untuk proyek emansipasi.

\section{Pokok Pikiran Antonio Gramsci (Hegemoni dan Pendidikan)}

Hegemoni dalam pengertian Gramsci adalah "a social condition in which all aspects of social reality are dominanated by supportive of a single class (livingstone 1976, 235) "single class" dalam konteks kita sekarang lebih tepat diganti dengan "dominant group" (kelompok dominan), unruk menggambarkan kompleksitas kekuasaan yang bermain. Konsep hegemoni bisa dipakai sebagai alat analisis untuk memahami mengapa kelompok-kelompok subordinat secara sukarela mau berasimilasi ke dalam pandangan dunia kelompok dominan, yang pada giliranya membuat kelompok ini menjadi mudah untuk terus melanggengkan dominasi dan kekuasaan mereka. Gramsci berpendat situasi ini memungkinkan kelompok dominan menerapkan apa yang disebut dengan "hegemoni" dengan demikian untuk mempertahankan posisi kelompok dominan selalu berupaya mengamankan persetujuan spontan kelompok marginal dengan cara menegosiasikan konsesus politik dan ideology (Nuryatno 2008, 32).

Proses hegemoni melibatkan penetrasi dan sosialisai nilai, keyakinan, sikap dan moralitas di masyarakat yang di mediasi oleh praktek-praktek sosial, politik dan ideologi. Ketika prinsip-prinsip ini diinternalisasi oleh masyarakat maka akan berubah menjadi common sense yang pada giliranya mendegradasi pikiran pikiran kritis masyarakat dan sebaliknya memperkuat status quo. Di sinilah bisa dipahami mengapa kaum tertindas secara tidak sadar berpartisipasi dalam proses dominasi dan mau bekerja sama dengan para penindas, ini terjadi karena masyarakat menganggap bahwa tindakan kelas yang berkuasa sebagai suatu yang natural dan normal serta sesuai dengan kepentingan mereka (Gramsci 2006, 36).

Proses hegemoni sebenarnya merupakan proses pembel- 
ajaran, agen-agen yang terlibat dalam hubungan edukatif ini adalah institusi-institusi yang turut membentuk masyarakat sipil, atau institusi-institusi sosial ideologis yang ikut mengkontruksi basis kultural kekuasaan, seperti hukum, pendidikan, agama, media massa dan lain sebagainya. Dengan demikian, institusi-institusi seperti ini tidaklah netral, tapi justru mendukung dan memperkuat hegemoni yang ada, termasuk di dalamnya dunia pendidikan.

Namun penting di catat konsep hegemoni tidaklah ekslusif milik kelas borjuis atau kelas dominan, dalam pandangan Gramsci, kelas pekerja bisa membangun hegemoninya dengan cara membuat aliansi dengan kelompok-kelompok minoritas dan kekuataan sosial yang lain berdasarkan prinsip saling menghormati. Masing masing kelompok diyakini punya kontribusi terhadap aliansi baru ini. Jika demikian halnya, sesungguhnya hegemoni bukanlah konsep statis tetapi dinamis.

\section{Pokok Pikiran Paulo Freire}

Pemikiran Freire adalah keberpihakanya pada kaum tertindas, kaum tertindas ini bisa bermacam-macam, terindas oleh rezim otoriter, tertindas oleh struktur sosial yang tidak adil dan diskriminatif, terindas karena warna kulit, gender, ras dan lain sebagainya. Paling tidak ada dua ciri orang tertindas: pertama, mereka mengalami alienasi dari diri dan lingkungan, mereka tidak bisa menjadi subjek yang otonom, tapi hanya mampu mengimitasi orang lain, kedua, mereka mengalami self-defreciation, mereka merasa bodoh, tidak mengetahui apa-apa. Padahal ketika mereka telah berinteraksi dengan dunia dan manusia lain maka sesungguhnya mereka tidak lagi menjadi bejana kosong melainkan telah menjadi makhluk yang mengetahui (Nuryatno 2008, 42).

Kemudian pertanyaan adalah bagaimana mengemansipasi mereka yang tertindas? Untuk menjawab pertanyaan tersebut, Freire berangkat dari konsep tentang manusia, baginya manusia adalah incomplete and unfinished beings. Untuk itulah manusia 
dituntut untuk selalu berusaha menjadi subjek yang mampu mengubah realitas eksistensinya. Menjadi subjek atau makhluk yang lebih manusiawi, dalam pandangan Freire adalah panggilan ontologis manusia. Sebaliknya, dehumanisasi adalah distorsi atas panggilan ontologism manusia. Filsafat pendidikan Freire bertumpu pada keyakinan bahwa manusia secara fitrah mempunyai kapasitas untuk mengubah nasibnya. Dengan demikian, tugas utama pendidikan sebenarnya adalah mengantarkan peserta didik menjadi subjek, untuk mencapai tujuan ini, proses yang harus mengandaikan dua gerakan ganda: meningkatkan kesadaran kritis peserta didik dan sekaligus berupaya mentransformasikan struktur sosial yang menjadikan penindasan itu berlangsung.

Sebab kesadaran manusia itu berproses secara dialektis antara diri dan lingkungan, ia punya potensi untuk berkembang dan mempengaruhi lingkungan, tapi ia juga bisa dipengaruhi dan dibentuk oleh struktur sosial, untuk itulah emansipasi dan transendensi tingkat kesadaran itu harus melibatkan dua gerakan ganda ini sekaligus. Idealitas di atas bisa dicapai jika proses pembelajaran didasarkan pada relasi subjek-sebjek, bukan subjek-objek. Tapi konsep ini tidak berarti hanya menjadikan guru sebagai fasilitator, karena ia harus terlibat bersama-sama dengan peserta didik dalam mengkritisi dan memproduksi ilmu pengetahuan. Guru dalam pandangan Freire, tidaklah hanya menjadi tenaga pengajar yang memberi instruksi kepada anak didik. Tapi mereka harus memerankan dirinya sebagai pekerja kultural, mereka harus sadar bahwa pendidikan itu mempunyai dua kekuatan sekaligus: sebagai aksi kultural untuk pembebasan atau sebagai aksi kultural untuk dominasi dan hegemoni, sebagai medium untuk mereproduksi status quo (Freire 2012, 16).

Jika pendidikan dipahami sebagai aksi kultural untuk pembebasan maka pendidikan tidak bisa dibatasi fungsinya hanya sebatas area pembelajaran di sekolah. Tidak bisa dibatasi fungsinya hanya sebatas area pembelajaran di sekolah. Tapi ia harus diperluas perannya dalam menciptakan kehidupan publik yang lebih demokratis, untuk itulah dalam pandangan Freire harus 
ada semacam kontekstualisasi pembelajaran di kelas, teks yang diajarkan di kelas harus dikaitkan dengan kehidupan nyata

\section{Critical Pedagogy Menuju Pendidikan yang Inklusif}

Pendidikan inklusif (inclusive education) belum banyak menjadi perhatian dalam pembahasan pendidikan kita pada hari ini. Padahal mau tidak mau, disadari atau tidak praktek-praktek diskriminasi selalu dekat dengan proses pendidikan formal. Tidak hanya dari segi akses yang sulit, namun juga telah menjadikan banyak orang di belahan bumi manapun ter-eksklusi dari pola mainstream pendidikan yang ada. seperti, di Afrika kaum perempuan tereksklusi dari sekolah mainstream yang ada, mereka mendapat perlakuan yang tidak adil dalam pendidikan. Akses mereka di bidang pendidikan sangat tidak sepadan dibanding laki-laki, di Eropa dan Amerika banyak warga imigran asal Spanyol, Karibia, Meksiko dan lain sebagainya harus kehilangan identitas budaya mereka harus kehilangan identitas dan budaya mereka akibat sistem pendidikan yang tidak mampu mengakomodasi kebutuhan-kebutuhan mereka. Mereka dipaksa berasimilasi dengan budaya local. Di Indonesia sendiri praktek-praktek diskriminasi pendidikan telah terjadi dari zaman kolonial sampai sekarang, dari terjadi diskriminasi pemerintah kolonial terhadap golongan pribumi untuk mendapatkan pendidikan, sampai di konteks sekrang akses pendidikan yang begitu sulit bagi orang-orang yang kurang mampu, maka fungsi dari pendidikan inklusif adalah gerakan intelektual sebagai wadah yang anti diskriminasi, sebuah wadah yang mampu mengakomodasi seluruh akses untuk mendapatkan ruang belajar oleh siapapun.

Banyaknya anak-anak yang terekslusi dari pendidikan inilah yang mendasari munculnya pendidikan inklusif. Pendidikan inklusif pada dasarnya adalah proses untuk membuat semua peserta didik, termasuk di dalamnya kelompok yang tereksklusi dapat belajar dan berpartisipasi secara efektif di sekolah mainstream tanapa ada yang terluka dan terdiskriminasi. Pendidikan inklusif sebenarnya persoalan politik kultural identitas dan per- 
bedaan. Pendidikan inklusif dilandaskan pada beberapa prinsip:

Pertama, setiap orang secara inheren punya hak terhadap pendidikan atas dasar kesamaan dan kesempatan. Ini adalah prinsip universal yang menjadi pijakan bagi semua bangsa-bangsa dunia. Tidak ada satupun bangsa yang menolak prinsip ini, meskipun dalam penerapanya, ada yang menerapkan secara penuh, setengah - setengah, atau minimalis. Banyak hal yang mempengaruhi perbedaan ini, terutama soal seberapa serius institusi Negara punya perhatian terhadap pendidikan. Seberapa jauh prinsip dasar ini menjadi jiwa dalam membuat kebijakan-kebijakan negara. Ini sebenarnya menyangkut visi peyelenggara negara, politisi masyarakat sispil dan elemen-elemen yang lain.

Kedua, tidak boleh ada peserta didik yang tereksklusi dan terdiskriminasi dalam pendidikan dengan alasan apapun, apakah ras warna kulit, gender, bahasa, agama, politik difabilitas atau lainya, eksklusi dan diskriminasi dalam pendidikan merupakan sesuatu yang riil terjadi di belahan bumi manapun, di negara majau sekalipun, di beberapa universitas terkemuka di amerika juga terjadi praktek diskriminasi, sebab yang mendominasi di universitas-universitas tersebut adalah kalangan menengah atas dan orang kulit putih, disini terjadi praktek diskriminasi dan eksklusi berdasar pada kelas sosial dan warna kulit.

Ketiga, semua anak pada dasarnya dapat belajar dan mendapat manfaat dari pendidikan, prinsip ini di dasari oleh keyakinan bahwa betapapun naïf dan bodohnya anak, dia dapat berkembang dan berubah, untuk menjadi pendidik yang baik, yang diperlukan di atas segalanya adalah keyakinan yang tinggi kepada manusia.

Keempat, sekolah merupakan pihak yang bertanggung jawab untuk menyediakan kebutuhan bagi peserta didiknya, bukannya peserta didik yang harus mengadaptasi kebutuhan sekolah. Seringkali yang menjadi patokan adalah pernyataan yang kedua dibanding yang pertama. Kebutuhan peserta didik disekolah sangat beragam, baik yang berupa kebutuhan fisik maupun non fisik, sekolah harus memperhatikan semua kebutuh- 
an ini dan memberikan yang terbaik agar kebutuhan-kebutuhan tersebut terpenuhi. Guru misalnya, harus bisa melihat beragam kompetensi yang dimiliki peserta didik.

Kelima, pandangan, opini dan pendapat peserta didik harus didengar dan diperhatikan. Prinsipnya adalah ketika manusia sudah dilahirkan di bumi dan berinteraksi dengan manusia yang lain maka ia telah menjadi makhluk yang mengetahui. Oleh karena itu, suara opini dan pendapat yang mereka sampaikan harus diapresiasi.

Keenam, perbedaan-perbedaan individual diantara peserta didik adalah sumber kekayaan dan keragaman, bukanlah sebuah masalah, diversitas memperkaya, bukanya menghambat atau memperlambat, proses pembelajaran. Tingkat kompetisi di antara peserta didik tentu beragam, disinilah kreativitas guru diperlukan untuk mencari pendekatan yang sesuai dengan karateristik dan kompetisi peserta didik.

Ketujuh, dasar pendidikan kritis bukanlah asimilasi, tapi apresiasi atas perbedaan. asimilasi adalah proses menghilangkan identitas kultural individu atas kelompok marginal agar sesuai dengan identitas kultural kelompok dominan. Proses ini bisa dilakukan lewat pendidikan. Pendidikan inklusif tidak dimaksudkan untuk mengasimilasi kultural seseorang, tapi bagaimana identitas tersebut terjaga, prinsip apresiasi menjadi penting pada wilayah ini.

\section{E. Catatan Penutup}

Semua unsur yang terlibat dalam institusi pendidikan, dari mulai penyelenggara administrasi pendidikan, pendidik dan peserta didik dosen-mahasiswa, guru-murid, harus memiliki pemahaman tentang critiqal pedagogy agar mampu membaca dan melihat fenomena-fenomen yang terjadi di dunia pendidikan kita pada hari ini, tidak hanya berdiam diri dan berpangku tangan terhadap masalah-masalah pendidikan saat ini, agar praktek-praktek eksklusi terhadap peserta didik bisa di tekan karna, kesempatan untuk mengenyam pendidikan adalah hak 
Aktualisasi Wacana Critical Pedagogy Menuju Pendidikan Inklusif

dari setiap warga negara dan dijamin oleh undang-undang. Dan terciptanya pendidikan yang inklusif atau pendidikan yang anti diskriminasi.

Pendidikan adalah suatu unsur penting yang harus dimiliki oleh setiap manusia karna pada hakekatnya tujuan dari pendidikan adalah untuk mencerdaskan, tidak terkecuali siapapun dia , bagaimana latar belakangnya dan seperti apa kondisi fisiknya pendidikan adalah milik semua orang, tapi ketika pendidikan tidak mampu lagi mengakomodasi secara keseluruhan ketika pendidikan dimandulkan oleh ideology pasar dan dikekang oleh kuasa negara maka critical pedagogy lah salah satu solusi yang layak di ajukan demi hilangnya eksklusi dalam pendidikan dan terciptanya pendidikan yang inklusif atau anti diskriminasi yang mampu mengakomodasi secara keseluruhan dalam dunia pendidikan.

\section{DAFTAR PUSTAKA}

Bourdieu, Pierre. 2016. Arena Produksi Kultural. Yogyakarta: Kreasi Wacana.

Freire, Paulo. 2011. Pendidikan Kaum Tertindas. Jakarta: LP3ES.

Gramsci, Antonio. 2006. Kritik terhadap Pembangunan Dunia Ketiga. Yogyakarta: Pustaka Pelajar.

Jay, Martin. 2005. Sejarah Mazhab Frankfrut. Yogyakarta: Kreasi Wacana.

Presetyo, Eko. 2010. Orang Miskin Dilarang Sekolah. Yogyakarta: Resist Book.

Nuryanto, Agus. 2010. Mazhab Pendidikan Kritis. Yogyakarta: Resist Book. 